\title{
Do Parents' Oral Health Literacy Levels Influence Their Response to Interventions to Improve Their Knowledge of Traumatic Dental Injuries?
}

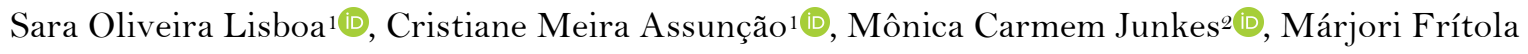 \\ Yokoyama $^{2}\left(\mathbb{D}\right.$, Ana Carolina Fernandes Couto ${ }^{\circledR}$, Fabian Calixto Fraiz ${ }^{1}$, Saul Martins Paiva ${ }^{\circledR}$, \\ Fernanda Morais Ferreira ${ }^{1}$ (1)
}

\begin{abstract}
${ }^{1}$ Department of Oral Health for Children and Adolescents, Federal University of Minas Gerais, Belo Horizonte, MG, Brazil.

${ }_{2}^{2}$ Department of Stomatology, Federal University of Paraná, Curitiba, PR, Brazil.
\end{abstract}

Author to whom correspondence should be addressed: Sara Oliveira Lisboa, Av. Antônio Carlos, Faculdade de Odontologia, 6627, Pampulha, Belo Horizonte, MG, Brazil. 31270-901. Phone: +55 31 34092470. E-mail: lisboasara.o@gmail.com.

Academic Editor: Wilton Wilney Nascimento Padilha

Received: 18 November 2019 / Accepted: 21 June 2020 / Published: 10 July 2020

How to cite this article: Lisboa SO, Assunção CR, Junkes MC, Yokoyama MF, Couto ACF, Fraiz FC, et al. Do parents'
oral health literacy levels influence their response to interventions to improve their knowledge of traumatic dental injuries?
Pesqui Bras Odontopediatria Clín Integr. 2020; 20:e5498. https://doi.org/10.1590/pboci.2020.134

\begin{abstract}
Objective: To measure the influence of oral health literacy (OHL) level in the improvement of knowledge about traumatic dental injuries (TDI) after an educational intervention. Material and Methods: A total of 257 parents of children aged $0-12$ years had their OHL level evaluated (BREALD-30). A leaflet with information about how to respond to TDI Emergency was developed and delivered to the parents. A questionnaire about attitudes towards TDI was administered before (TDIQ1) and after (TDIQ2) parents read the educational leaflet. The hypotheses were evaluated by non-parametric tests, correlation analysis and logistic regression. Results: The mean OHL score was 21.6. The means of correct answers in TDIQ1 were 5.5 and $5.9(\mathrm{p}=0.066)$ and in TDIQ2 were 6.6 and $7.7(\mathrm{p}=0.003)$ between the groups with inadequate and marginal/adequate OHL, respectively. In the logistic regression, the total score of BREALD-30 and the maximum number of correct answers in $\mathrm{TDIQ}_{2}$ maintained statistical association when adjusted for schooling, gender, age of the parents, family income and the number of correct answers in the first application of the questionnaire. Conclusion: The level of OHL influenced the improvement of parents' knowledge about emergency care in cases of TDI in children from an educational intervention using a leaflet, and this intervention was more effective for parents with adequate OHL.
\end{abstract}

Keywords: Health Literacy; Oral Health; Tooth Injuries; Health Education; Child. 


\section{Introduction}

Health literacy has been described by the World Health Organization as "social and cognitive skills that determine the motivation and ability of individuals to access, understand and use information to promote and maintain good health" [1]. The consequences of difficulty in accessing, understanding and applying information provided by health professionals have been studied worldwide [1-3], and correlate with worse health conditions and poor access to health services [4]. In the dental context, oral health literacy can be defined as the individual's ability to communicate with dental service providers, understand the causes of poor oral health, follow medication prescriptions, understand self-care and adopt associated practices, find their way to a dental clinic for treatment, as well as registering for dental care [5].

Low caregiver education is associated with worse health conditions and is a risk factor for dental caries in children [6-9]. Similarly, inadequate oral health literacy (OHL) is related to worse oral health conditions in adults and adolescents, less retention of health information, and, in parents and caregivers, is a risk factor for increased caries in their children [10-19].

Understanding information is important in the dynamic teaching-learning process and, therefore, of great importance in preventive and curative health actions. In cases of traumatic dental injuries (TDI), quick and well-executed actions, provided by prior guidance from a health professional, are fundamental to determining a good prognosis for the affected tooth and reducing treatment costs [20].

It is estimated that more than a billion living individuals have already had some type of TDI, with the worldwide prevalence in permanent dentition being around $15 \%$ and in primary dentition 23\% [21]. TDI is still associated with a high impact on oral health-related quality of life [22].

Most occurrences of TDI happen in a school environment or at home [23-25], with the first care being offered by an adult companion. However, the knowledge of parents and educators about emergency care for TDI is still limited [25-28].

Among educational measures to promote health, written materials are of great value and are frequently used in preventive campaigns, favoring an increase in the autonomy and skills of individuals, including in situations relevant to TDI [29-32].

This study aimed to measure oral health literacy's influence in improving the knowledge of parents or caregivers about emergency care for traumatic dental injuries through educational intervention using a leaflet.

\section{Material and Methods}

\section{Study Design}

An intervention study was developed to assess the influence of the level of literacy in the oral health of parents or caregivers in improving their knowledge of emergency care in cases of traumatic dental injuries in children. The administration of the TDI questionnaire, the reading of the educational leaflet and the assessment of OHL level through the BREALD-30 all took place in the single session. The data collection team comprised an examiner and three assistants who received training in administering the questionnaire, delivery of the leaflet and clarification of respondents' concerns.

\section{Study Population}

The study sample comprised 257 parents/caregivers of children aged from 0 to 12 years undergoing medical care at two Health Units (HU) in the Guaraituba region of Colombo, Brazil, between June and September 2012. 
The Colombo city has an estimated population of 243,000 inhabitants and has 28 Health Units, 25 of which are categorized as serving the Family Health Strategy (FHS). The location of the HUs selected for the study was determined by the Health Department. The selected HUs are in areas of higher population density, and selected with consideration for the structure and flow of patients in these units.

The criteria for participation in the research were: literacy, did not present cognitive impairment, no reported or perceived vision/hearing problems, and without obvious signs of alcohol or drug intoxication at the time of interview.

Intervention

The educational leaflet was based on material from the dental trauma education and prevention campaign of the Brazilian Society of Dental Traumatology [33]. It addressed the actions to be taken in the emergency room in situations of avulsion, intrusion, extrusion (front of the leaflet) and fracture (back of the leaflet) in the primary and permanent dentition. The A4 size leaflet had colorful illustrations of the situations and simple and direct language.

\section{Oral Health Literacy Assessment - BREALD-30}

Participants' oral health literacy measured using the Brazilian version of the BREALD-30 instrument [34]. The interviewer was pre-trained in BREALD-30 administration, following the method proposed previously [35].

The BREALD-30 instrument classifies adults' oral health literacy level through word recognition. It contains 30 words related to dentistry, and associated with treatment and prevention of oral conditions, etiology and anatomy. The words must be read aloud by the participant. For each word pronounced correctly, the interviewer assigns 1 (one) point, while a score of o (zero) is assigned for words pronounced incorrectly. The final score, obtained by summing the scores assigned to each word, ranges from o (lowest literacy level) to 30 (highest literacy level).

Traumatic Dental Injuries Questionnaire (TDIQ)

To assess the level of knowledge about traumatic dental injuries, the caregivers answered a questionnaire about actions to be taken in the emergency room of children in case of TDI, including avulsion, extrusion, intrusion and dental fracture. The questionnaire (TDIQ) contained 10 multiple-choice questions, each with 4 or 5 answer options. Respondents also could describe another action, if they did not consider any of the offered solutions to be correct. Five questions addressed situations trauma to permanent dentition, and five questions addressed trauma to deciduous dentition.

The questionnaire administration lasted approximately 15 minutes and took place in a private room while the participants waited for their child's medical care in HU rooms. There were two moments when the TDIQ was applied: before reading the educational leaflet (TDIQ1) and after reading it (TDIQ2).

Based on the guidelines of the Brazilian Society of Dental Traumatology [33], the responses to TDIQ1 and TDIQ2 were scored; each answer received a 0 when incorrect and 1 when correct. The total possible score hence ranged from o to 10, with lower scores corresponding to a lower level of knowledge. Each participant's pre- and post-test scores were compared to measure acquisition of new information from the educational leaflet. 
Statistical Analysis

For bivariate analyses, the participants' OHL level was classified as inadequate (BREALD-30 score $\leq$ 16) or as marginal or adequate (BREADLD-30 score $\geq 17$ ), using the lowest quintile as the cutoff point [15]. As the TDIQ scores did not show a normal distribution, Mann-Whitney non-parametric tests were used to compare various sociodemographic groups, and the Wilcoxon non-parametric test was used to compare TDIQ pre- and post-test scores. The Mann-Whitney test was also used to compare the BREALD-30 scores associated with responses to each item in the TDIQ pre- and post-tests. The association between the OHL level and perfect performance in the TDIQ post-test (all 10 questions correct vs. fewer than 10 questions correct), was investigated using multiple binary logistic regression, with a model adjusted for sociodemographic variables and the pre-test score. A significance level of $5 \%$ was adopted for all analyses. Data were analyzed using SSPS, version 20.0 (IBM Corp., Armonk, NY, USA).

\section{Ethical Considerations}

The study was conducted under approval by the Research Ethics Committee of the Health Sciences Sector at Federal University of Paraná (SD Registry: 1247.172.11.10, CAAE: 0171.0.091.000-11).

\section{Results}

The average age of participants was 33.8 years $( \pm 11.7)$ and ranged from 15 to 75 years. Their children's ages ranged from 1 month to 12 years, with an average age of 6 years $( \pm 3.7)$. Of the total sample, $91.1 \%$ of participants were female; $74.3 \%$ of them were mothers of children in medical care at the Health Unit. Participants' gross monthly family incomes at the time of the interview ranged from no income at all up to an income of $\mathrm{R} \$ 10,000$ monthly, with an average of $\mathrm{R} \$ 1,850$, approximately 2.96 times the minimum wage for the current year (SD 1260).

Literacy scores, as measured by the BREALD-30 instrument, averaged 21.6, with a median score of 23 , and ranging from 3 to 30 .

No association was found between TDIQ 1 score and the other variables such as gross monthly family income, age, education and civil status of the person in charge, degree of kinship or occupation in the area of health (Table 1). On the other hand, there was an association found between the TDIQ2 post-test score and years of education received (Mann-Whitney test; $\mathrm{p}<0.001$ )

Table 1. TDI questionnaire scores before and after exposure to the educational leaflet, analysed by socioeconomic variables.

\begin{tabular}{|c|c|c|c|c|c|c|c|}
\hline \multirow[b]{2}{*}{ Variables } & \multirow[b]{2}{*}{$\mathrm{N}$} & \multicolumn{3}{|c|}{ TDIQ1 Pre-Test } & \multicolumn{3}{|c|}{ TDIQ2 Post-Test } \\
\hline & & Median & Range & p-value* & Median & Range & p-value* \\
\hline \multicolumn{8}{|l|}{ Kinship } \\
\hline Mother & 191 & 6.0 & $1-8$ & 0.307 & 8.0 & $2-10$ & 0.837 \\
\hline Others & 66 & 6.0 & $3-10$ & & 7.7 & $5-10$ & \\
\hline \multicolumn{8}{|l|}{ Gender } \\
\hline Female & 234 & 6.0 & $1-8$ & 0.100 & 8.0 & $5-10$ & 0.382 \\
\hline Male & 23 & 5.0 & $3-10$ & & 8.0 & $2-10$ & \\
\hline \multicolumn{8}{|l|}{ Marital Status } \\
\hline Married/Stable Relationship & 204 & 6.0 & $1-10$ & 0.732 & 8.0 & $2-10$ & 0.789 \\
\hline Others & 53 & 6.0 & $3-8$ & & 8.0 & $5-10$ & \\
\hline \multicolumn{8}{|l|}{ Education } \\
\hline$>8$ Years & 144 & 6.0 & $1-10$ & 0.051 & 8.0 & $2-10$ & $<0.001$ \\
\hline
\end{tabular}




\begin{tabular}{|c|c|c|c|c|c|c|c|}
\hline$\leq 8$ Years & 113 & 5.5 & $3-8$ & & 7.0 & $3-10$ & \\
\hline \multicolumn{8}{|c|}{ Health Occupation } \\
\hline Yes & 13 & 5.0 & $1-8$ & 0.302 & 8.0 & $5-9$ & 0.553 \\
\hline No & 244 & 6.0 & $3-10$ & & 8.0 & $2-10$ & \\
\hline
\end{tabular}

TDIQ1 = Pre-test (1st administration) of the questionnaire on emergency care in case of traumatic dental injuries, before exposure to the educational leaflet; $\mathrm{TDIQ}^{2}=$ Post-test (2nd administration) of the questionnaire on emergency care in case of traumatic dental injuries after exposure to the educational leaflet; *Mann-Whitney test.

The mean TDIQ1 pre-test score was 5.87 and, after reading the leaflet, the mean TDIQ 2 post-test score was significantly higher at 7.51 (Wilcoxon test; $\mathrm{p}<0.001$ ).

Table 2 describes the TDIQ1 and TDIQ2 scores, according to the level of OHL. A significant difference was found between the pre- and post-tests $(\mathrm{p}<0.001)$ and, within the post-test results, a significant difference between parents/caregivers at different OHL levels ( $p=0.003$ ); parents/caregivers with marginal/adequate OHL obtained, on average, a higher score after reading the educational leaflet.

Table 2. TDIQ scores, analyzed by OHL level.

\begin{tabular}{|c|c|c|c|c|c|c|c|}
\hline \multirow{3}{*}{ OHL Group } & \multicolumn{6}{|c|}{ Score (Number of Correct Answers) } & \multirow{3}{*}{ p-value ${ }^{\#}$} \\
\hline & \multicolumn{3}{|c|}{ TDIQ 1} & \multicolumn{3}{|c|}{ TDIQ $^{2}$} & \\
\hline & Average & Median & Range & Average & Median & Range & \\
\hline Inadequate OHL $(\mathrm{n}=43)$ & 5.49 & 5 & $3-8$ & 6.65 & 7 & $2-10$ & $<0.001$ \\
\hline Marginal/Adequate OHL $(\mathrm{n}=214)$ & 5.95 & 6.0 & $1-10$ & 7.68 & 8 & $4-10$ & $<0.001$ \\
\hline p-value* & & 0.066 & & & 0.003 & & \\
\hline
\end{tabular}

TDIQ1 = Pre-test (1st administration) of the questionnaire on emergency care in case of traumatic dental injuries, before exposure to the educational leaflet; TDIQ2 = Post-test (2nd administration) of the questionnaire on emergency care in case of traumatic dental injuries, after exposure to the educational leaflet; *Mann-Whitney test; \#Wilcoxon test.

Table 3 describes the BREALD-30 scores of parents/caregivers according to their performance (error/success) on each item of the TDIQ test, before and after exposure to the educational leaflet. In the TDIQ 1 pre-test, questions 5 and 10 showed a significant difference in BREALD-30 scores. In TDIQ 2 posttest, there were significant differences between the BREALD-30 scores for questions 4, 5, 6, 7, 9 and 10 (Table 3). According to the performance in the responses to the questionnaire, the difference in OHL level is more evident after exposure to the educational leaflet.

Table 3. Total score of BREALD-30 according to the answer to each item of the questionnaire, before and after exposure to the educational leaflet.

\begin{tabular}{|c|c|c|c|c|c|c|c|}
\hline \multirow{3}{*}{ Questionnaire Items } & \multirow{3}{*}{ Answer } & \multicolumn{6}{|c|}{ BREALD-30 Score } \\
\hline & & \multicolumn{3}{|c|}{ TDIQ1 pre-test } & \multicolumn{3}{|c|}{ TDIQ 2 post-test } \\
\hline & & Median & Range & p-value & Median & Range & p-value \\
\hline \multirow{2}{*}{$\begin{array}{l}\text { 1) What do you think should be done if your } \\
\text { child is hit and the deciduous tooth loosens } \\
\text { from its place? }\end{array}$} & Right & 23 & $3-30$ & \multirow[t]{2}{*}{0.212} & 23 & $3-30$ & \multirow[t]{2}{*}{0.473} \\
\hline & Wrong & 23 & $7-29$ & & 21 & $8-30$ & \\
\hline 2) How long after your child is hit and the & Right & 23 & $5-30$ & 0.933 & 23 & $5-30$ & \multirow[t]{2}{*}{0.128} \\
\hline $\begin{array}{l}\text { deciduous tooth loosens, should you see a } \\
\text { dentist? }\end{array}$ & Wrong & 22 & $3-30$ & & 20 & $3-30$ & \\
\hline \multirow{2}{*}{$\begin{array}{l}\text { 3) What do you think should be done if your } \\
\text { child is hit and the deciduous tooth moves } \\
\text { into the gum? }\end{array}$} & Right & 23 & $3-30$ & 0.078 & 23 & $3-30$ & \multirow[t]{2}{*}{0.886} \\
\hline & Wrong & 20 & $7-30$ & & 23 & $7-30$ & \\
\hline 4) What do you think should be done if your & Right & 24 & $7-30$ & \multirow[t]{2}{*}{0.535} & 24 & $7-30$ & \multirow[t]{2}{*}{0.003} \\
\hline $\begin{array}{l}\text { child is hit and the deciduous tooth moves } \\
\text { out of the gum, but without loosening?? }\end{array}$ & Wrong & 23 & $3-30$ & & 21 & $3-30$ & \\
\hline 5) What do you think should be done if your & Right & 23 & $3-30$ & 0.035 & 23 & $5-30$ & 0.002 \\
\hline
\end{tabular}




\begin{tabular}{|c|c|c|c|c|c|c|c|}
\hline $\begin{array}{l}\text { child is hit and the deciduous tooth breaks a } \\
\text { piece? }\end{array}$ & Wrong & 22 & $5-30$ & & 20 & $3-29$ & \\
\hline $\begin{array}{l}\text { 6) What do you think should be done if your } \\
\text { child is hit and the permanent tooth loosens } \\
\text { from its place? }\end{array}$ & Wrong & 23 & $3-30$ & 0.531 & 19 & $3-27$ & $<0.001$ \\
\hline $\begin{array}{l}\text { 7) How long after your child suffers a blow } \\
\text { and the permanent tooth loosens, should you } \\
\text { see a dentist? }\end{array}$ & Wrong & 21 & $\begin{array}{l}5-30 \\
3-29\end{array}$ & 0.077 & 23 & $\begin{array}{l}5-30 \\
3-23\end{array}$ & 0.002 \\
\hline $\begin{array}{l}\text { 8) What do you think should be done if your } \\
\text { child is hit and the permanent tooth moves } \\
\text { into the gum? }\end{array}$ & Wrong & 20 & $\begin{array}{l}3-30 \\
7-30\end{array}$ & 0.055 & 23 & $\begin{array}{l}3-30 \\
7-30\end{array}$ & 0.876 \\
\hline $\begin{array}{l}\text { 9) What do you think should be done if your } \\
\text { child is hit and the permanent tooth moves } \\
\text { out of the gum, but without loosening? }\end{array}$ & Wrong & 23,5 & $\begin{array}{l}7-30 \\
3-30\end{array}$ & 0.642 & 23,5 & $3-30$ & $<0.001$ \\
\hline $\begin{array}{l}\text { 10) What do you think should be done if } \\
\text { your child is hit and the permanent tooth } \\
\text { breaks a piece? }\end{array}$ & $\begin{array}{l}\text { Right } \\
\text { Wrong }\end{array}$ & 23 & $\begin{array}{l}8-30 \\
3-30\end{array}$ & 0.002 & 23 & $\begin{array}{l}5-30 \\
3-29\end{array}$ & $<0.001$ \\
\hline
\end{tabular}

TDIQ1 = Pre-test (1st administration) of the questionnaire on emergency care in case of traumatic dental injuries, before exposure to the educational leaflet; TDIQ2 2 Post-test (2nd administration) of the questionnaire on emergency care in case of traumatic dental injuries, after exposure to the educational leaflet; *Mann-Whitney test.

Table 4 shows the results of multiple binary logistic regression, in which the maximum number of correct answers in the TDIQ2 post-test and the total score of BREALD-30 maintained a statistical association when adjusted for education, gender, age of the person in charge, family income and the number of correct answers in the first application of the questionnaire. The sex and age of the caregiver also gave a significant association with the maximum number of correct answers in TDIQ2.

Table 4. Multiple logistic regression for sociodemographic factors associated with the maximum number of correct answers in TDIQ2.

\begin{tabular}{lcccc}
\hline \multicolumn{1}{c}{ Variables } & & p-value & Multiple Model OR (95\% CI) \\
\hline Caregiver Schooling & $>8$ Years & 1 & 0.995 & $0.00(0.00-0.00)$ \\
& $\begin{array}{c}<\text { Years } \\
\text { Responsible Gender } \\
\text { Male }\end{array}$ & 1 & $<0.001$ & $0.03(0.00-0.19)$ \\
Female & & & \\
Responsible Age & & 0.002 & $0.86(0.79-0.95)$ \\
Family Income (Brazilian Reais) & & 0.518 & $1.00(0.99-1.00)$ \\
BREALD Total Score & & $<0.001$ & $1.49(1.19-1.86)$ \\
TDIQ1 Score & & 0.042 & $1.63(1.02-2.60)$ \\
\hline
\end{tabular}

TDIQ1 = Pre-test (1st administration) of the questionnaire on emergency care in case of traumatic dental injuries, before exposure to the educational leaflet; TDIQ $2=$ Post-test (2nd administration) of the questionnaire on emergency care in case of traumatic dental injuries, after exposure to the educational leaflet; Adjustment measures: Hosmer \& Lemeshow test: $\mathrm{p}=0.733$; -2 likelihood log $=82,013$; Chisquare statistics of the model (Omnibus Test): $\mathrm{p}<0.001$; Ranking chart: Cases concentrated in columns at the ends of the chart, with few cases wrongly classified.; Residue analysis: Model with no case with standardized residue value in excess of \pm 3 and with only $2 \%$ of cases with standardized residue value in excess of $\pm 2.5 .100 \%$ of Cook's influence statistic values, leverage point and DFBeta $<|1|$.

\section{Discussion}

The average BREALD-30 score in this study was 21.6, similar to that found in other studies developed in the state of Paraná, of 21.9 [36] and 22.3 [17]. The first of these was also involving parents/caregivers of children, in this case, aged 4-5 years and enrolled in public schools in the city of Curitiba [36]. The second study examined a sample of 175 pregnant women and evaluated their acquisition and retention of information about nutrition and oral hygiene of children under 2 years old, with a follow-up of up to 4 weeks. Both studies found an association between inadequate OHL and unfavorable outcomes in completing questionnaires and acquiring/retaining information, respectively [17,36]. 
The average BREALD-30 score was also similar to that of parents/caregivers in the North American population - 21.8 - with children 3 to 18 years old (average age 6.6 years), lower parental OHL level was associated with worse oral health outcomes [37].

In the present study, sociodemographic variables were not associated with the questionnaire scores before the educational intervention (TDIQ1). After the educational intervention, the number of correct answers in the questionnaire (TDIQ2) was significantly higher for caregivers with more than eight years of education.

A very interesting finding was that there was an increase in the TDIQ 2 score even for parents/caregivers with inadequate/marginal OHL, albeit smaller than in parents/caregivers with adequate OHL.

The higher number of correct responses after reading the educational leaflet observed in general suggests that a leaflet is an effective tool for educational health promotion measures. The educational leaflet has the advantages of easy handling, low cost, possibility of being read at a time and place convenient for the reader, readable more than once allowing for gradual absorption of the content, are self-explanatory, and are easily distributed [29,31]. The disadvantages are reading problems, whether due to an inability of the reader or to inadequacy of the material [29,31].

In turn, better performance from the educational intervention of parents with adequate OHL compared to parents with inadequate/marginal OHL is consistent with the results of other studies $[16,17,36-$ 42], which found an association of lower OHL levels with the highest rates of missing dental appointments, worse oral health conditions in adults, worse perceived oral health of their children, poor oral health outcomes in their children, negative health attitudes, less adherence to recommendations for healthy habits, greater difficulty filling out questionnaires.

In the present study, the difference in the OHL levels according to the performance on the questionnaire was more evident after exposure to the educational leaflet: this difference was statistically significant for 2 items out of 10 in TDIQ1, and for 6 items out of 10 in TDIQ 2 . In two questions (5 and 10), which addressed less complex injuries such as enamel and/or dentin fracture, parents with better performance (correct) before (TDIQ1) and after reading the leaflet educational (TDIQ2) exhibited significantly higher BREALD-30 scores (higher OHL) than those with worse performance (incorrect).

On the other hand, individuals with higher BREALD-30 scores may be more likely to respond to a call for action and make incorrect decisions in situations that do not require a specific action. As seen for questions 3 and 8, when the BREALD-30 scores were compared between parents who got these questions right or wrong in the post-test TDIQ2, there was no significant difference between these scores. Perhaps this has happened because, unlike other questions in which the answer is to take some action in the face of trauma, in these two questions (cases of dental intrusion in deciduous and permanent dentition), the appropriate action is to wait rather than intervening immediately $[33,42,43]$. It is important to reinforce the guidelines regarding emergency care in cases of TDI, especially concerning dental intrusion in deciduous and permanent dentition, since even parents with higher OHL scores did not answer the associated questions correctly.

In our study, the chance of correctly answering all questions about emergency care after an educational intervention increased with the increase in the level of OHL, even after adjusted in the multivariate analysis for sociodemographic differences, which might be confounding factors. It is worth mentioning that including the variable "TDIQ1 score" in the model allowed an adjustment also for other conditions capable of influencing the outcome and which were not directly assessed in the study. 
Educational health promotion activities must be sensitive to each community's capacity for understanding and existing levels of OHL. It is important to consider that the present study was carried out in the public health network of a specific region in Colombo, Brazil. It is plausible that, given wide variations in access to health services, educational level and social factors, other populations have different OHL characteristics and will hence need other educational approaches. Our results suggest that parents/caregivers with adequate OHL and who have undergone an educational intervention through leaflets may be better able to act in the emergency room in cases of traumatic dental injuries. However, more studies are still needed, with other types of educational interventions, in other populations and with more representative samples, especially on a theme as broad as traumatic dental injuries. It would also be interesting to develop longitudinal studies that assess the retention of knowledge over time, rather than only immediately after reading the educational leaflet.

\section{Conclusion}

Intervention through the reading of an educational leaflet led to a performance increase in a questionnaire assessing the knowledge of parents/caregivers about traumatic dental injuries. After the intervention, the questionnaire performance of parents/caregivers with an adequate level of oral health literacy was higher than that of parents/caregivers with inadequate oral health literacy. The chance of correctly answering the entire questionnaire after the educational intervention increased with the increase in the level of oral health literacy, regardless of other sociodemographic characteristics of the parents/caregivers.

\section{Authors' Contributions}

\begin{tabular}{|c|c|c|}
\hline SOL & (iD) $0000-0002-7785-9927$ & Formal Analysis and Writing - Original Draft Preparation. \\
\hline CMA & (D) $0000-0002-1464-7812$ & Formal Analysis, Writing - Review and Editing and Supervision. \\
\hline MCJ & (iD) $0000-0001-8902-9202$ & Investigation and Writing - Review and Editing. \\
\hline MFY & (iD) $0000-0001-9187-5870$ & Investigation and Writing - Review and Editing. \\
\hline $\mathrm{ACFC}$ & (iD) $0000-0002-3025-3493$ & Investigation, Formal Analysis and Writing - Review and Editing. \\
\hline $\mathrm{FCF}$ & (iD) $0000-0001-5290-7905$ & Conceptualization, Methodology, Writing - Review and Editing and Supervision. \\
\hline SMP & (D) $0000-0002-3968-1638$ & Formal Analysis, Writing - Review and Editing and Supervision. \\
\hline FMP & (D) $0000-0003-2981-5644$ & $\begin{array}{l}\text { Conceptualization, Methodology, Formal Analysis and Writing - Review and } \\
\text { Editing. }\end{array}$ \\
\hline
\end{tabular}

\section{Financial Support}

None.

\section{Conflict of Interest}

The authors declare no conflicts of interest.

\section{References}

[1] Kutner ME, Greenberg E, Jin Y, Paulsen C. The Health Literacy of America's Adults: Results From the 2003 National Assessment of Adult Literacy (NCES 2006-483). U.S. Department of Education. Washington, DC: National Center for Education Statistics.

[2] Carthery-Goulart MT, Anghinah R, Areza-Fegyveres R, Bahia VS, Brucki SMD, Damin A, et al. Performance of a Brazilian population on the test of functional health literacy in adults. Rev Saude Publica 2009; 43(4):631-8. https://doi.org/10.1590/s0034-89102009005000031 
[3] HLS-EU Consortium (2012): Comparative Report of Health Literacy in Eight EU Member States. The European Health Literacy Survey HLS-EU (Second Revised and Extended Version, Date July 22th, 2014). Available from: http://www.health-literacy.eu. [Accessed on September 04, 2019].

[4] Adams RJ, Stocks NP, Wilson DH, Hill CL, Gravier S, Kickbusch I, et al. Health literacy: a new concept for general practice? Aust Fam Physician 2009; 38(3):144-7.

[5] Parker EJ, Jamieson LM. Associations between Indigenous Australian oral health literacy and self-reported oral health outcomes. BMC Oral Health 2010; 10(1):3. https://doi.org/10.1186/1472-6831-10-3

[6] Hallett KB, O’Rourke PK. Social and behavioural determinants of early childhood caries. Aust Dent J 2003; 48(1)1:2733. https://doi.org/10.1111/j.1834-7819.2003.tb00005.x

[7] Sanders LM, Federico S, Klass P, Abrams MA, Dreyer B. Literacy and child health: a systematic review. Arch Pediatr Adolesc Med 2009; 163(2):131-40. https://doi.org/10.1001/archpediatrics.2008.539

[8] Sarumathi T, Saravana Kumar B, Manjula D, Hemalatha VT, Aarthi Nisha V. Prevalence, severity and associated factors of dental caries in 3-6 year old children. Clin Diagn Res 2013; 7(8):1789-92. https://doi.org/ 10.7860/JCDR/2013/6201.3277

[9] Zhou Y, Yang JY, Lo ECM, Lin HC. The contribution of life course determinants to early childhood caries: a 2-year cohort study. Caries Res 2012; 46(2):87-94. https://doi.org/10.1159/000335574

[10] Divaris K, Lee JY, Baker AD, Vann Jr WF. Caregivers' oral health literacy and their young children's oral healthrelated quality-of-life. Acta Odontol Scand 2012; 70(5):390-7. https://doi.org/ 10.3109/00016357.2011.629627

[11] Firmino RT, Martins CC, Faria LDS, Paiva SM, Granville-Garcia AF, Fraiz FC, et al. Association of oral health literacy with oral health behaviors, perception, knowledge, and dental treatment related outcomes: a systematic review and meta-analysis. J Public Health Dent 2018; 78(3):231-45. https://doi.org/10.1111/jphd.12266

[12] Firmino RT, Ferreira FM, Martins CC, Granville-Garcia AF, Fraiz FC, Paiva SM. Is parental oral health literacy a predictor of children's oral health outcomes? systematic review of the literature. Int J Paediatr Dent 2018; 28(5):45971. https://doi.org/10.1111/ipd.12378

[13] Lee JY, Divaris K, Baker AD, Rozier RG, Vann Jr WF. The relationship of oral health literacy and self-efficacy with oral health status and dental neglect. Am J Public Health. 2012; 102(5):923-9. https://doi.org/10.2105/AJPH.2011.300291

[14] Montes GR, Bonotto DV, Ferreira FM, Menezes JVNB, Fraiz FC. Caregiver's oral health literacy is associated with prevalence of untreated dental caries in preschool children. Cien Saude Coletiva 2019; 24(7):2737-44. https://doi.org/10.1590/1413-81232018247.18752017

[15] Vann Jr WF, Lee JY, Baker D, Divaris K. Oral health literacy among female caregivers. J Dent Res 2010; 89(12):1395-400. https://doi.org/10.1177/0022034510379601

[16] Vann Jr WF, Divaris K, Gizlice Z, Baker AD, Lee JY. Caregivers' health literacy and their young children's oralhealth-related expenditures. J Dent Res 2013; 92(7 Suppl):55S-62S. https://doi.org/10.1177/0022034513484335

[17] Vilella KD, Fraiz FC, Benelli EM, Assunção LRS. Oral health literacy and retention of health information among pregnant women: a randomised controlled trial. Oral Health Prev Dent 2017; 15(1):41--8. https://doi.org/10.3290/j.ohpd.a37712

[18] Dutra LC, Lima LCM, Neves ETB, Gomes MC, Araújo LJS, Forte FDS, et al. Adolescents with worse levels of oral health literacy have more cavitated carious lesions. PLoS One 2019; 14(11):e0225176. https://doi.org/10.1371/journal.pone.0225176

[19] Neves ETB, Dutra LC, Gomes MC, Paiva SM, Abreu MHNG, Ferreira FM, et al. The impact of oral health literacy and family cohesion on dental caries in early adolescence. Community Dent Oral Epidemiol 2020; 48(3):232-9. https://doi.org/10.1111/cdoe.12520

[20] Andreasen JO, Lauridsen E, Gerds TA, Ahrensburg SS. Dental trauma guide: a source of evidence-based treatment guidelines for dental trauma. Dent Traumatol 2012; 28(5):345-50. https://doi.org/10.1111/j.1600-9657.2011.01059_1.x

[21] Petti S, Glendor U, Andersson L. World traumatic dental injury prevalence and incidence, a meta-analysis — One billion living people have had traumatic dental injuries. Dent Traumatol 2018; 34(2):71-86. https://doi.org/10.1111/edt.12389

[22] Silva-Oliveira F, Goursand D, Ferreira RC, Paiva PCP, Paiva HN, Ferreira EF, et al. Traumatic dental injuries in Brazilian children and oral health-related quality of life. Dent Traumatol 2018; 34(1):28-35. https://doi.org/10.1111/edt.12358

[23] Mota LQ, Targino AGR, Lima MGGC, Farias JFG, Silva ALA, Farias JFG. Evaluation of dental trauma in schoolchildren of the city of João Pessoa, PB, Brazil. Pesqui Bras Odontopediatria Clin Integr 2011; 11(2):217-22. https://doi.org/10.4034/PBOCI.2011.112.11

[24] Granville-Garcia AF, Menezes VA, Lira PIC. Prevalência e fatores sociodemográficos associados ao traumatismo dentário em préescolares. Odontol Clín-Cient 2006; 5(1):57-64. [In Portuguese]

[25] Sousa DL, Moreira Neto JJS, Gondim JO, Bezerra Filho JG. Prevalence of dental trauma in children attending the Federal University of Ceará. Rev Odonto Ciênc 2008; 23(4):355-9. 
[26] Stangler ML, Vanni JR, Echer R. Quantitative evaluation of students' knowledge in the college of pedagogy - UPF on avulsion-reimplant. RFO UPF 2002; 7(1):23-8.

[27] Curylofo PA, Lorencetti KT, Silva SRC. Evaluation of teachers' knowledge concerning tooth avulsion. Arq Odontol 2012; 48(3):175-80.

[28] Bittencourt AM, Pessoa OF, Silva JM. Evaluation of teacher's knowledge about dental avulsion management in children. Rev Odontol UNESP 2008; 37(1):15-9.

[29] Moreira MF, Nóbrega MML, Silva MIT. Written communication: contribution for the elaboration of educational material in health. Rev Bras Enferm 2003; 56(2):184-8. https://doi.org/10.1590/s0034-71672003000200015.

[30] Arikan V, Sönmez H. Knowledge level of primary school teachers regarding traumatic dental injuries and their emergency management before and after receiving an informative leaflet. Dent Traumatol 2012; 28(2):101-7. https://doi.org/10.1111/j.1600-9657.2011.01042.x

[31] Young C, Wong KY, Cheung LK. Effectiveness of educational poster on knowledge of emergency management of dental trauma - part 1. Cluster randomized controlled trial for primary and secondary school teachers. PLoS One 2013; 8(9):e74833. https://doi.org/10.1371/journal.pone.0074833

[32] Frítola M, Couto ACF, Spinardi D, Junkes MC, Fraiz FC, Ferreira FM. Do educational leaflets improve the knowledge of parents when faced with traumatic dental injuries? Arq Odontol 2014; 50(4):178-84.

[33] Sociedade Brasileira de Traumatologia Dentária. Campanha de educação e prevenção do trauma dentário. Available from: http://www.sbtd.org.br. [Accessed on April 18, 2014].

[34] Junkes MC, Fraiz FC, Sardenberg F, Lee JY, Paiva SM, Ferreira FM. Validity and reliability of the Brazilian version of the Rapid Estimate of Adult Literacy in Dentistry - BREALD-30. PLoS One 2015; 10(7):1-11. https://doi.org/10.1371/journal.pone.0131600

[35] Vilella KD, Assunção LRS, Junkes MC, Menezes JVNB, Fraiz FC, Ferreira FM. Training and calibration of interviewers for oral health literacy using the BREALD-30 in epidemiological studies. Braz Oral Res 2016; 30(1):e90. https://doi.org/10.1590/1807-3107BOR-2016.vol30.0090

[36] Firmino RT, Fraiz FC, Montes GR, Paiva SM, Granville-Garcia AF, Ferreira FM. Impact of oral health literacy on self-reported missing data in epidemiological research. Community Dent Oral Epidemiol 2018; 46(6):624-30. https://doi.org/10.1111/cdoe.12415

[37] Garrett GM, Citi AM, Gansky SA. Parental functional health literacy relates to skip pattern error and to child oral health. J Calif Dent Assoc 2012; 40(5):423-30.

[38] Baskaradoss JK. The association between oral health literacy and missed dental appointments. J Am Dent Assoc 2016; 147(11):867-74. https://doi.org/10.1016/j.adaj.2016.05.011

[39] Blizniuk A, Ueno M, Zaitsu T, Kawaguchi Y. Association of oral health literacy with oral health behaviour and oral health status in Belarus. Community Dent Health 2015; 32(3):148-52.

[40] Bridges SM, Parthasarathy DS, Wong HM, Yiu CKY, Au TK, McGrath CPJ. The relationship between caregiver functional oral health literacy and child oral health status. Patient Educ Couns 2014; 94(3):411-6. https://doi.org/10.1016/j.pec.2013.10.018

[41] Calvasina P, Lawrence HP, Hoffman-Goetz L, Norman CD. Brazilian immigrants' oral health literacy and participation in oral health care in Canada. BMC Oral Health 2016; 16:18. https://doi.org/10.1186/s12903-016-0176-1

[42] Day P, Flores MT, O'Connell A, Abbott PV, Tsilingaridis G, Fouad AF, et al. International Association of Dental Traumatology guidelines for the management of traumatic dental injuries: 3. Injuries in the primary dentition. Dental Traumatology 2012; 28:174-82. https://doi.org/10.1111/edt.12576

[43] DiAngelis AJ, Andreasen JO, Ebeleseder KA, Kenny DJ, Trope M, Sigurdsson A, et al. International Association of Dental Traumatology guidelines for the management of traumatic dental injuries: 1. Fractures and luxations of permanent teeth. Dent Traumatol 2012; 28(1):2-12. https://doi.org/10.1111/j.1600-9657.2011.01103.x 